\title{
CYTOMORPHOMETRIC ANALYSIS OF EXFOLIATIVE PALATAL MUCOSAL CELLS IN REVERSE SMOKERS IN 4 VILLAGES OF SRIKAKULAM DISTRICT, ANDHRA PRADESH - AN OBSERVATIONAL EXFOLIATIVE STUDY
}

\author{
Sirigala Lavanya1, Peddengatagari Suresh ${ }^{2}$
}

1 Professor In-Charge, Department of Oral Pathology, Government Dental College and Hospital, Kadapa. ${ }^{2}$ Associate Professor, Department of Periodontics, Government Dental College and Hospital, Kadapa.

\section{ABSTRACT}

Squamous cell carcinoma of palate is found to be the rarest of all the cancers. But the prevalence of palatal cancers in Srikakulam and Visakhapatnam districts (Coastal districts of Andhra Pradesh) was found to be $0.1 \% 1,2$ and noticed to be associated with the habit of reverse smoking in these geographic areas. These palatal cancers were found to arise from the pre-existing precancerous lesions namely Excrescences, White patches and Red areas, which were designated as Reverse smoker's lesions.

\section{AIM OF THE STUDY}

An observational cytomorphometric analysis study has been undertaken in this region to study quantitatively nuclear diameter, cell diameter and nuclear-to-cytoplasmic ratio from exfoliative smears of various reverse smoker's lesions to assess the type of reaction of palatal mucosal cells to the heat generated during reverse smoking.

\section{MATERIALS AND METHODS}

Materials used were mouth mirror, tongue depressor, wooden spatula, glass slides, 95\% alcohol, rapid PAP kit, Coplin jars, DPX mountant, xylene, coverslips, microscope and micrometre. The smears were collected using wooden spatula from various palatal lesions and fixed in 95\% alcohol. Staining of smears was done using rapid PAP kit. The cellular diameter and nuclear diameter of the cells were measured using micrometre and microscope.

\section{RESULTS}

The mean cellular diameter of White areas and Red areas was decreased compared to normal mucosa cells and the nuclear diameter was increased compared to normal mucosa cells. Both the diameters of both the lesions were nearing to carcinoma cells. The cellular and nuclear diameter of the excrescences were increased when compared to normal mucosa and carcinoma cells.

\section{CONCLUSION}

Excrescences represent proplastic and hyperplastic reaction of palatal surface epithelium, whereas white areas and red areas represent premalignant changes of palatal surface epithelium.

\section{KEYWORDS}

Palatal Cancers, Reverse Smoker's Lesions, Excrescences, White Patches, Red Areas, Cytomorphometry, Exfoliative Smears.

HOW TO CITE THIS ARTICLE: Lavanya S, Suresh P. Cytomorphometric analysis of exfoliative palatal mucosal cells in reverse smokers in 4 villages of Srikakulam district, Andhra Pradesh - an observational exfoliative study. J. Evolution Med. Dent. Sci. 2016; 5(69):4945-4951, DOI: $10.14260 /$ jemds/2016/1124

\section{INTRODUCTION}

Tobacco usage is found to be the main reason for oral cancer, which is recognized as one among the ten most common cancers in the world. It occurs in different parts of the mouth with different frequency depending upon the type of tobacco usage $^{1}$ (Figure 1). The rarest oral site is found to be palate, but still high prevalence of palatal cancer in Srikakulum and Visakhapatnam districts was noticed by many research workers. This was found to be associated with the habit of reverse smoking practiced in this geographic area. $2,3,4,5$ (Figure 2).

The palatal changes produced by reverse smoking are multimorphic consisting of several components namely

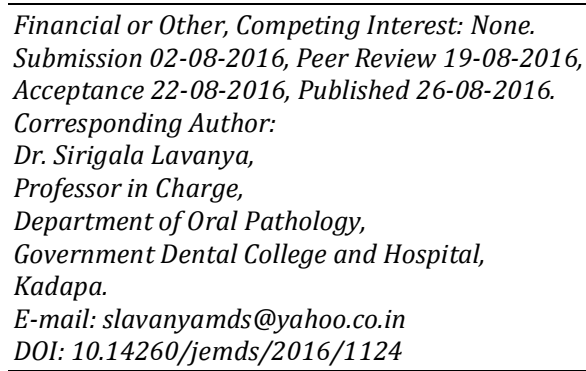

Palatal keratosis, Excrescences, Red patches, Ulceration and finally Carcinoma. ${ }^{1,3,4,5}$ The malignant potential of these lesions varies and cellular changes in these lesions can be observed in the exfoliated cells. These palatal changes were due to both tobacco by-products and heat generated above $120^{\circ} \mathrm{C}$ during reverse chutta smoking.

The optimal outcome in the management of any malignancy is dependent upon the early recognition and timely diagnosis. Technique of exfoliative cytology has got its own importance as an early diagnostic tool. Exfoliative cytology is a non-invasive diagnostic technique, in which exfoliative cells are smeared and assessed for physiological and pathological changes.6,7

The cells examined as smear are either manually scraped or they are cells which are spontaneously exfoliated as natural process. The smear obtained can be analysed quantitatively and qualitatively. Quantitative methods include assessment of DNA cytophotometry, nuclear cytoplasmic ratio, cell diameter, nuclear diameter, cell volume, cell density, etc. Qualitative methods include assessment of cellular and nuclear hyperchromatism, mitosis, shape of cells, etc. ${ }^{7}$ 
Of these parameters, cytomorphometric changes that are the nuclear and cellular areas and ratio of nuclear to cellular areas have been shown to be significant in the diagnosis of oral cancer. Many previous exfoliative studies proved that the decrease in cellular diameter, increase in nuclear diameter and increase in nuclear to cellular ratio were noticed in the smears from normal cells to malignant cells. This fact is considered in the present exfoliative cytomorphometric study to assess the changes in reverse palatal lesions through exfoliated palatal mucosal cells.

\section{AIM}

An observational non-invasive study has been undertaken after Institutional Ethical Committee approval to evaluate quantitatively the cellular diameter, nuclear diameter and nuclear to cellular ratio of exfoliated mucosal cells from different palatal lesions in reverse smokers. This cytomorphometry of exfoliative palatal mucosal cells was done to assess the nature of reaction in terms of malignant status of palatal mucosa in reverse chutta smoking.

\section{MATERIALS AND METHODS}

Steps followed in this case-control observational study in reverse smokers in 4 villages of Srikakulum District, Andhra Pradesh, India, are

1. Screening and Sample selection.

2. Smear collection and staining.

3. Cytomorphometric analysis.

4. Statistical analysis of the result.

\section{Study Materials}

Materials used were mouth mirror, tongue depressor, wooden spatula, glass slides, 95\% alcohol, rapid PAP kit, Coplin jars, DPX mountant, xylene, coverslips, microscope and micrometre [Figures 7, 8, 9 and 10].

\section{Study Methodology}

Criteria for sample selection is that all the subjects must be habituated to reverse chutta smoking with no other tobacco, alcohol habits and no other systemic complaints. Villagers were informed about the study and those came voluntarily were only considered as study subjects.

The persons were interviewed and screened with their willingness at home in the four villages of Srikakulum district, Andhra Pradesh. The information about the number, frequency and the duration of chutta smoking amongst reverse smokers was obtained, followed by the examination of the oral cavity in the day light. Subjects were divided as follows.

\section{SAMPLE STUDY GROUPS}

\section{Group A: Cases}

1. Case Group I: Patients with Excrescences of Palate (Figure No. 3) - 25 Nos.

2. Case Group II: Patients with White patches of Palate (Figure No. 4) - 25 Nos.

3. Case Group III: Patients with Red areas of Palate (Figure No. 5) - 25 Nos.

\section{Group B: Controls}

4. Control Group I: Normal palate in non-smokers - 10 Nos.
5. Control Group II: Patients with Squamous Cell Carcinoma of Palate (Figure 6) - 10 Nos.

The smears were collected using wooden spatula from various palatal lesions and fixed in 95\% alcohol. Staining of smears was done using rapid PAP kit. The cellular diameter and nuclear diameter of the cells was measured using micrometre and microscope.

The word morphometry means "measurement of form." On the other hand, "Planimetry" is a term used to denote measurement of geometrical features of structures in a two dimensional image, although these structures themselves originally may not be two-dimensional. Materials required for morphometry are compound light microscope (Magnus), Eyepiece micrometre (ERMA, Japan), stage micrometre (ERMA, Japan) (Figures 11 and 12).

The eyepiece micrometre must be standardized before starting the analysis, insert the eyepiece micrometre scale inside the eyepiece. Place the stage micrometre resting on the field stop on the stage. Select 40X objective and focus on the stage micrometre.

Determine the number of divisions of the eyepiece scale to an exact number of divisions of the stage micrometre.

1000 Eyepiece Divisions were found to Coincide with 28 Divisions. The Value of each Eyepiece Division was calculated as Follows

- 100 stage divisions $=1 \mathrm{~mm}=1000 \mu$.

- 28 stage divisions $=100$ eyepiece divisions $=280$.

- $\quad$ Therefore, 1 eyepiece division $=2.8 \mu$.

Once the micrometres adjusted, remove the stage micrometre. Then, focus on the cells in the stained smears in the field of vision and determine the number of eyepiece divisions exactly covered by the nucleus and the cytoplasm. Beginning at one end of the smear, moving horizontally and at the level and again moving horizontally and at the level and again moving horizontally in the opposite direction. Only cells that were fully included in the field of vision and with clearly defined cellular and nuclear outlines were selected (Figure no. 14). Cells that were clumped or folded were not considered for the analysis, because they could not give appropriate measurements (Figure No. 13). Measurements of the nuclear and cytoplasmic diameter were obtained in the perpendicular axes of the nuclei and cells respectively. The average of the values from the both axes was calculated and recorded as the Mean Nuclear Diameter (ND) and the mean Cytoplasmic Diameter (CD). The ratio of the nuclear diameter to cytoplasmic diameter was calculated and recorded as the $\mathrm{N}$ :C ratio; 25 cells were counted per slide. The values were statistically analysed.

\section{Statistical Analysis}

One Way ANOVA test was used for analysis of various parameters $\mathrm{CD}, \mathrm{ND}$ and $\mathrm{N}: \mathrm{C}$ ratio in relation to cases and controls. Tukey-HSD procedure was used to identify the significance at $5 \%$ level among various study groups. Student's ' $t$ ' test was used to evaluate the $p$-value in CD, ND and $\mathrm{N}: \mathrm{C}$ among various study groups. The level of significance was set as $p$ value $\leq 0.05$. Data was reported as mean and standard deviations. 


\section{RESULTS}

In the study group $\mathrm{A}$, cytomorphometric changes of exfoliative palatal epithelial cells of excrescences (Case group I) showed significant increase in Mean Nuclear Diameter (ND), Cell Diameter (CD) and nuclear-to-cytoplasmic ratio $(\mathrm{N}: \mathrm{C})$ compared to red patches and white patches (TukeyHSD procedure - significant at $5 \%$ level) (Table 1). In study group B, the control group II showed significant decrease in Cell Diameter (CD) ( $p$ value $<0.0001$ ), significant increase in Nuclear Diameter (ND) ( $p$ value - 0.005) than Control group I (Normal palatal mucosa in non-smokers) (Table 2). The mean cellular diameter was significantly increased ( $p$ value $<0.005$ ) and mean nuclear diameter ( $p$ value $<0.005$ ) was significantly increased in study group A - cases when compared to study group B - control group I (p value - 0.005) (Table 3). The mean nuclear cytoplasmic ratio was increased in study group A when compared to study group B - control group I ( $p$ value $<0.005$ ) (Table 3). The mean cellular diameter was significantly increased ( $p$ value $<0.005$ ) and mean nuclear diameter was significantly decreased ( $p$ value $<0.005$ ) in study group A than control group II (Table 4) in study group $B$. The mean nuclear cellular ratio was decreased in study group A when compared to control group II in study group B ( $\mathrm{p}$ value $<0.005$ ) (Table 4).

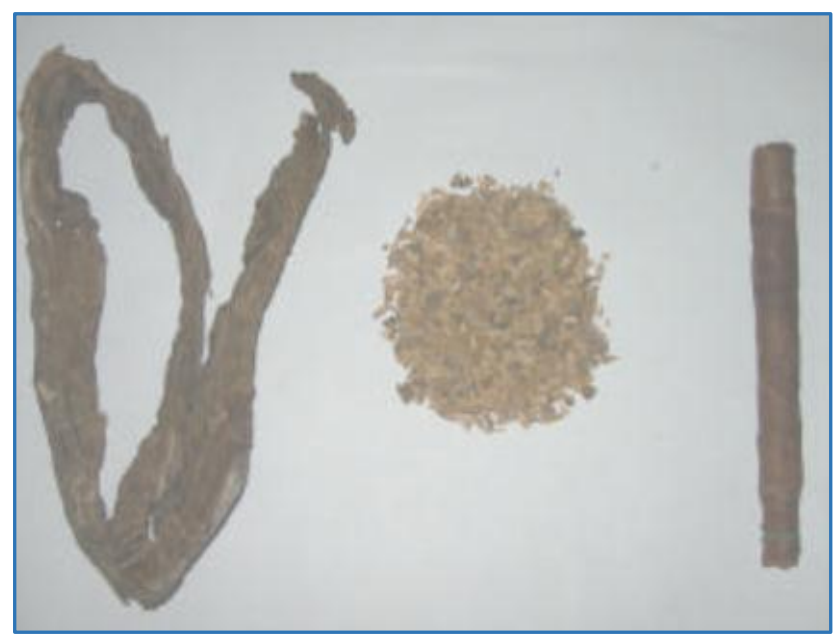

Fig. 1: Tobacco Leaf, Powder and Chutta

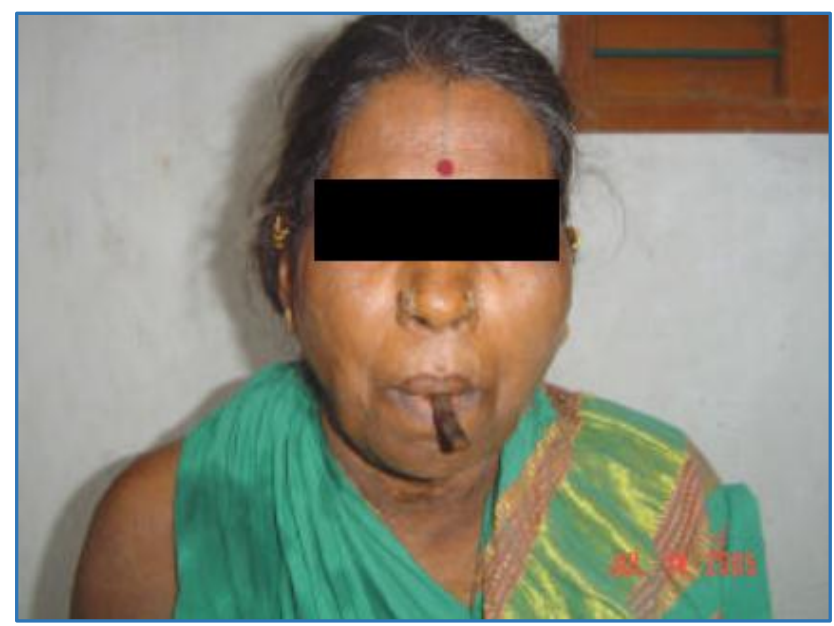

Fig. 2: Female Reverse Smoker

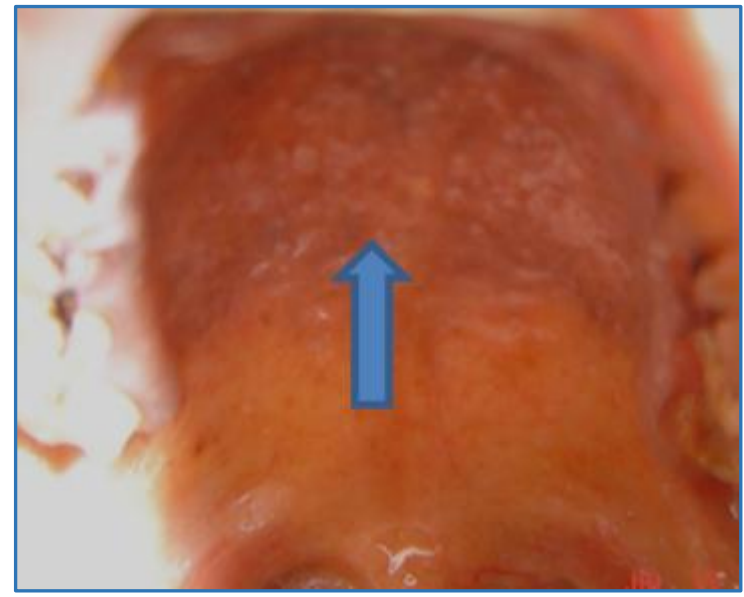

Fig. 3: Excrescences of Palate

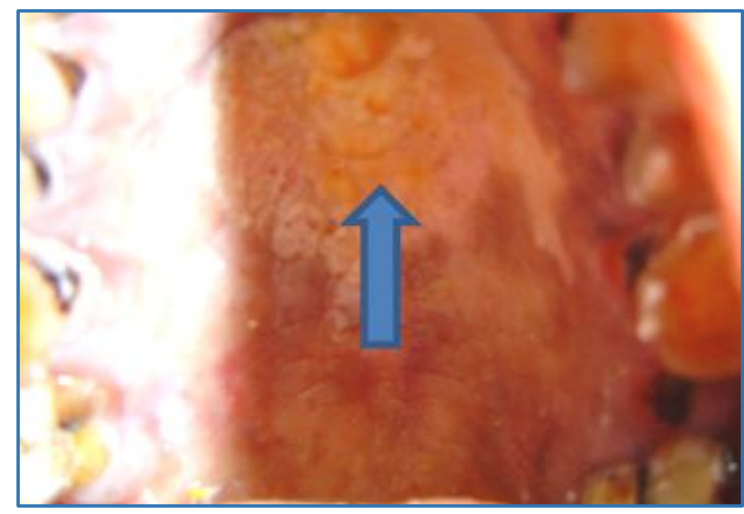

Fig. 4: White Patch of Palate

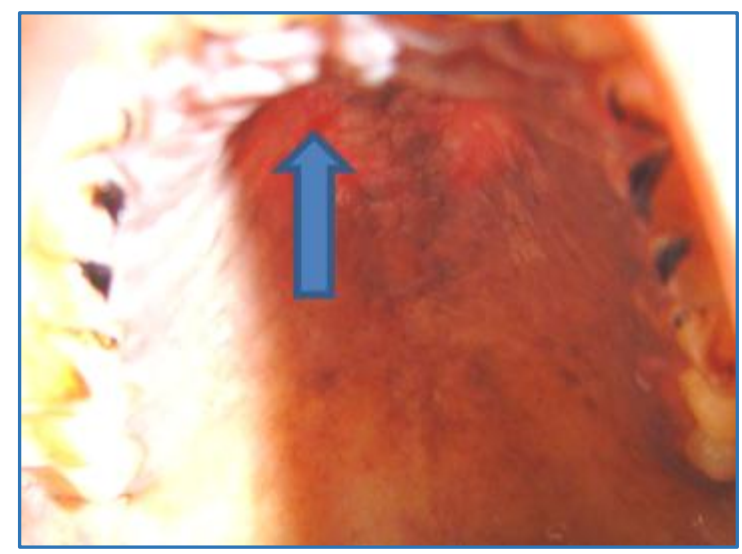

Fig. 5: Red Areas of Palate

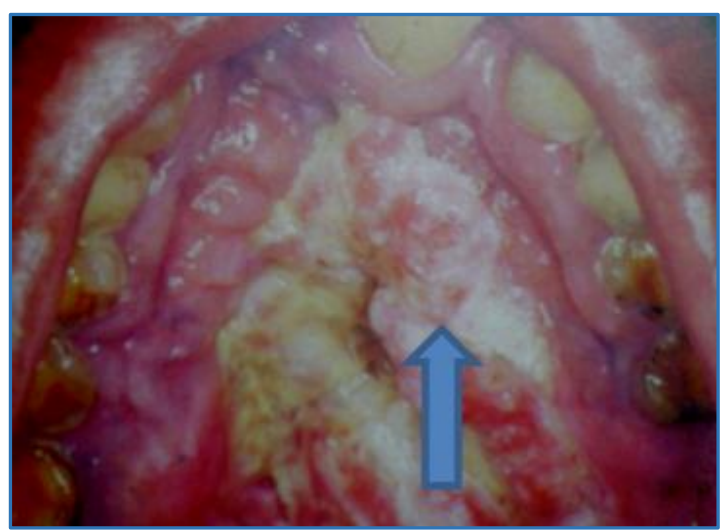

Fig. 6: Squamous Cell Carcinoma of Palate 


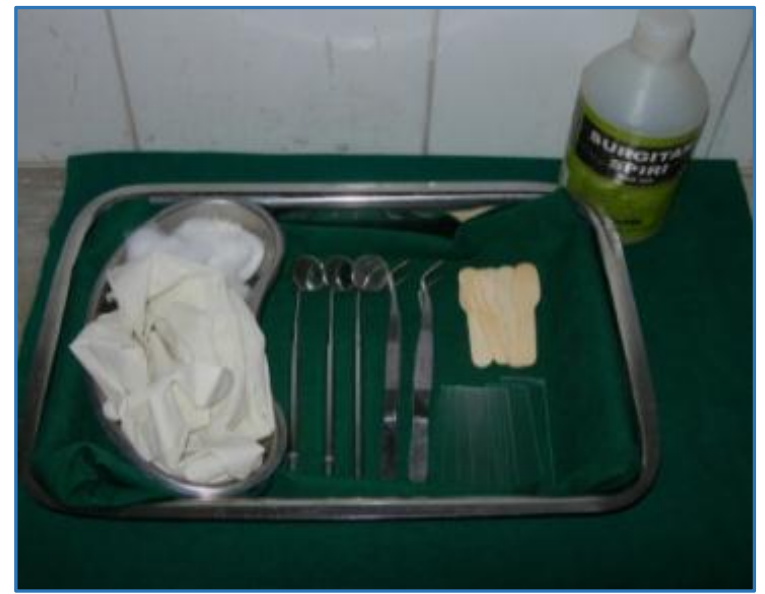

Fig. 7: Materials used in the Study

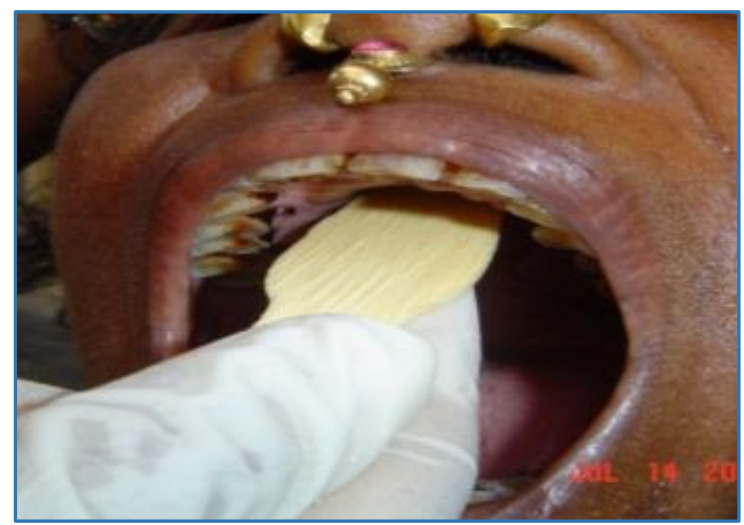

Fig. 8: Smear Collection using Ice-Cream Stick

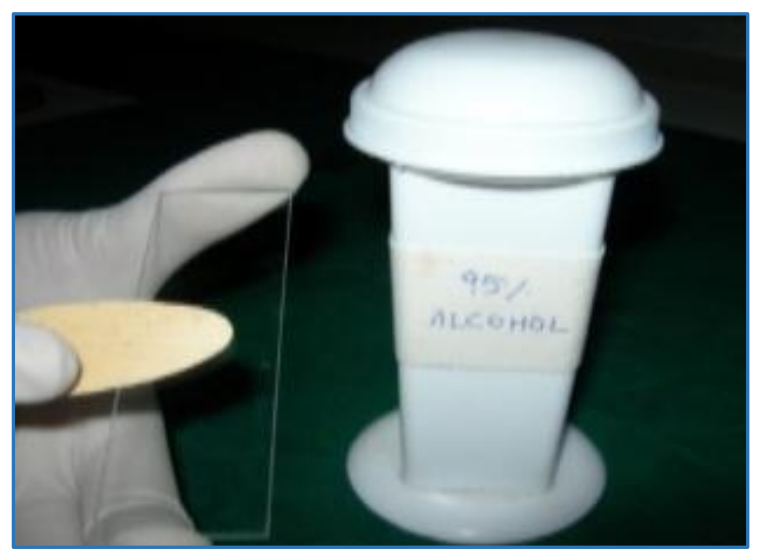

Fig. 9: Fixation of the Smear with 95\% Alcohol

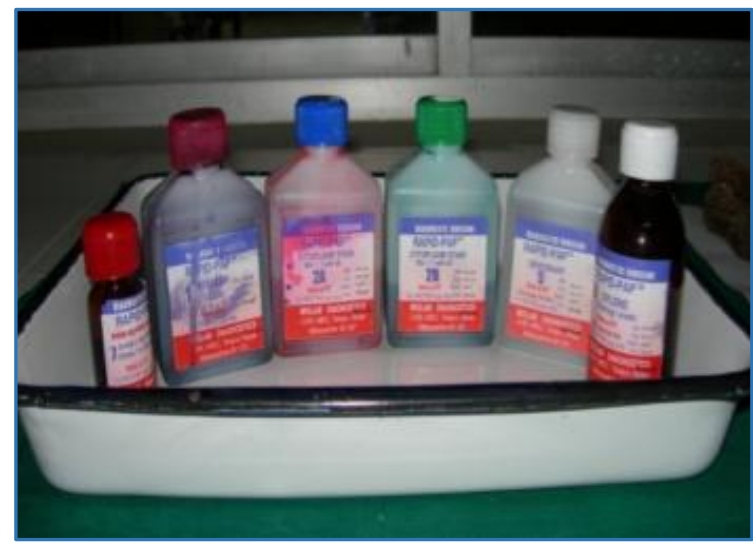

Fig. 10: Rapid Pap Kit

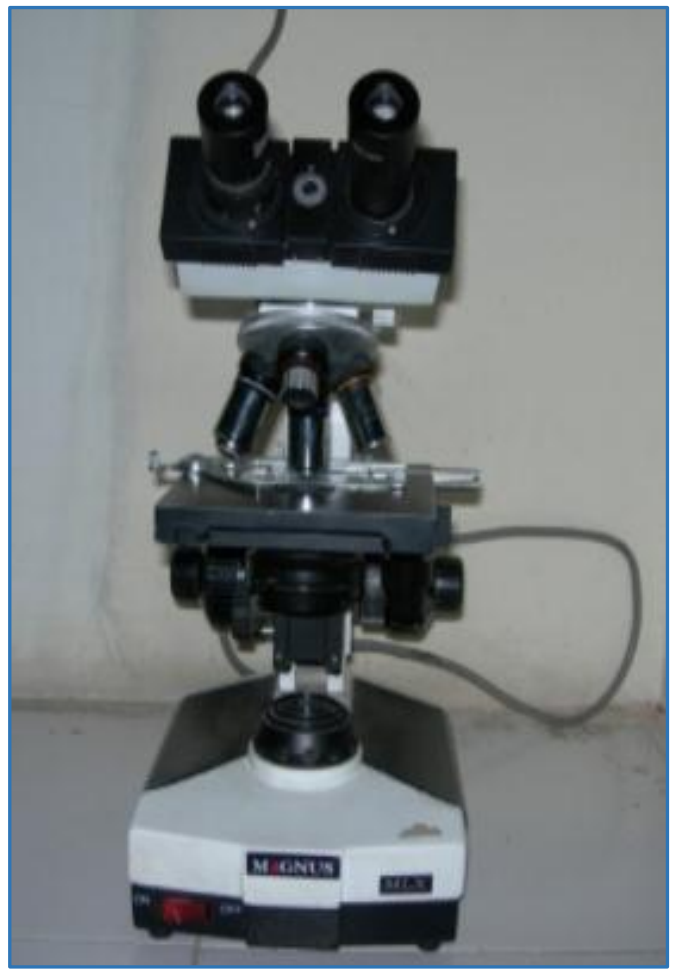

Fig. 11: Binocular Microscope

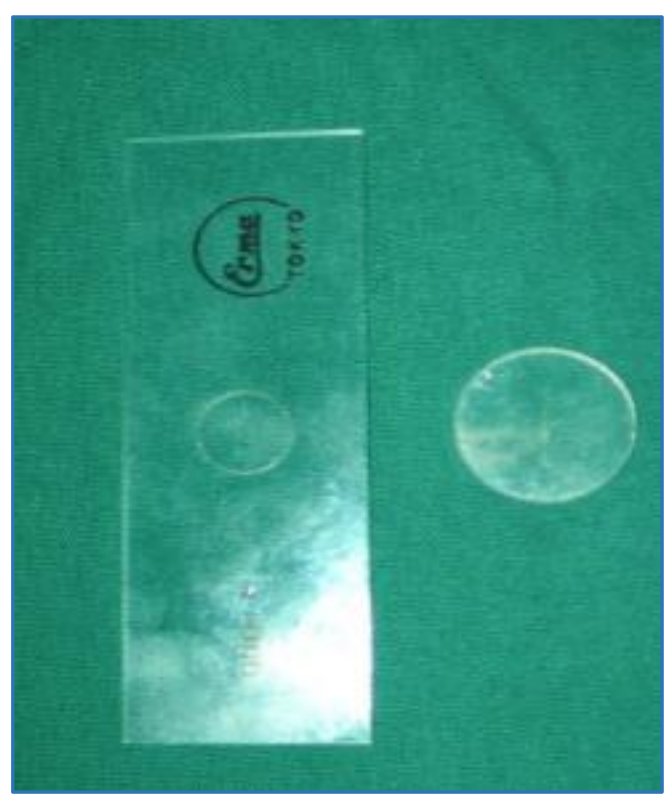

Fig. 12: Micrometres

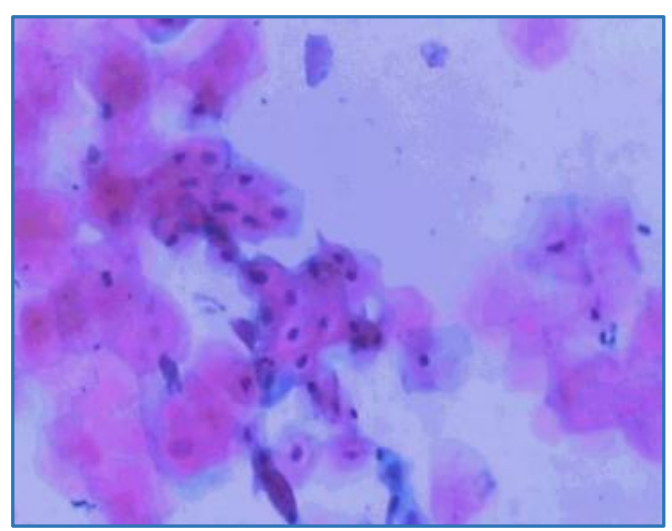

Fig. 13: Exfoliative Smears 


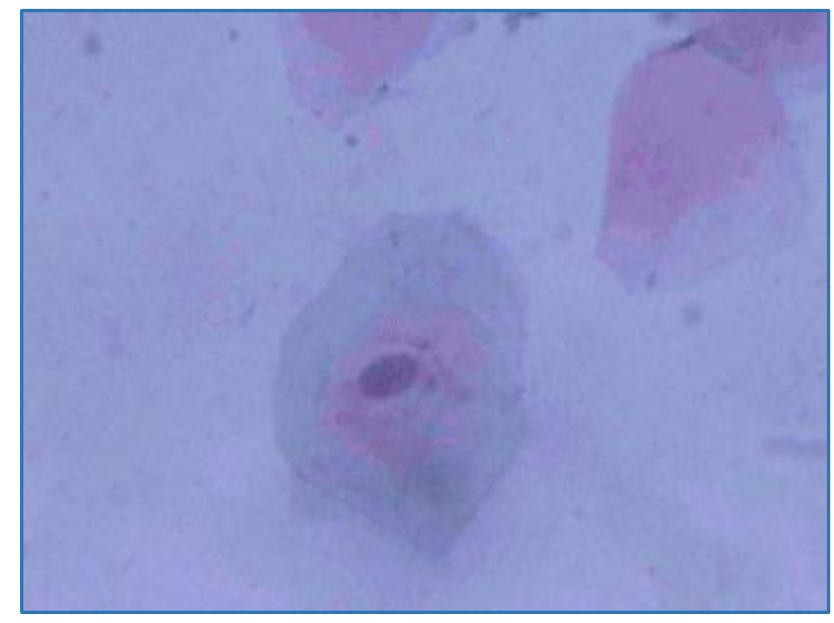

Fig. 14: Individual Cell

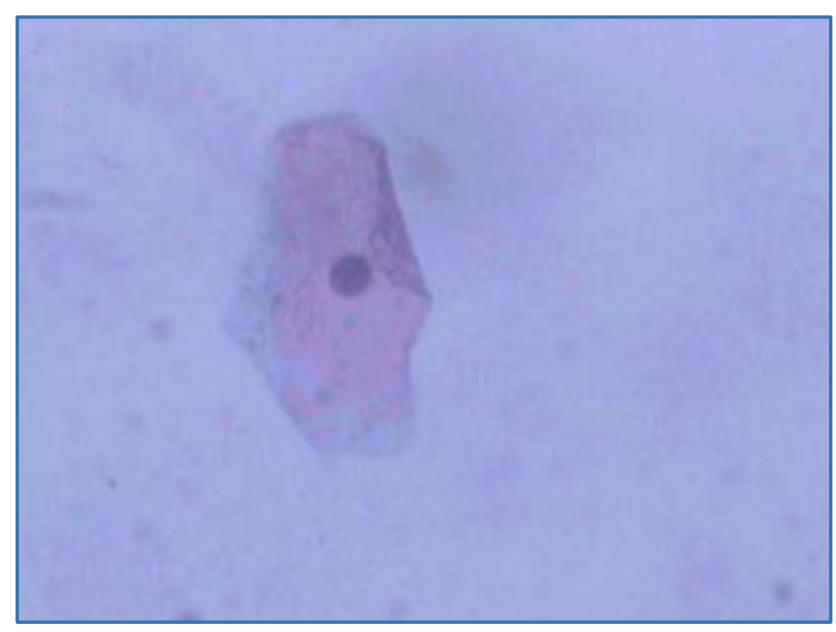

Fig. 15: Clumped Cells

\section{RESULTS}

\begin{tabular}{|c|c|c|c|c|}
\hline $\begin{array}{l}\text { Para- } \\
\text { meters }\end{array}$ & $\begin{array}{c}\text { Study } \\
\text { Group } \\
\text { A-Cases }\end{array}$ & Mean \pm SD & P-value & $\begin{array}{c}{ }^{*} \text { Significant } \\
\text { Groups } \\
\text { at } 5 \% \text { Level }\end{array}$ \\
\hline \multirow{3}{*}{ CD } & I & $63.25 \pm 3.22$ & \multirow{3}{*}{$<0.0001(\mathrm{~S})$} & \multirow{3}{*}{$\begin{array}{l}\text { *I VS II, III } \\
\text { II VS III }\end{array}$} \\
\hline & II & $53.96 \pm 4.75$ & & \\
\hline & III & $148.28 \pm 5.10$ & & \\
\hline \multirow{3}{*}{ ND } & I & $13.37 \pm 1.08$ & \multirow{3}{*}{$0.001(\mathrm{~S})$} & \multirow{3}{*}{$\begin{array}{l}* \text { I VS II } \\
\text { III VS II }\end{array}$} \\
\hline & II & $11.96 \pm 1.75$ & & \\
\hline & III & $13.17 \pm 1.34$ & & \\
\hline \multirow{3}{*}{$\mathrm{N}: \mathrm{C}$} & I & $0.21 \pm 0.02$ & \multirow{3}{*}{$<0.0001(\mathrm{~S})$} & \multirow{3}{*}{ * III VS I, II } \\
\hline & II & $0.22 \pm 0.02$ & & \\
\hline & III & $0.27 \pm 0.04$ & & \\
\hline \multicolumn{5}{|c|}{$\begin{array}{c}\text { Table 1: Comparison of Mean and Standard Deviation } \\
\text { of Parameters among Study Group A - Cases }\end{array}$} \\
\hline
\end{tabular}

${ }^{*}$ S-Statistically Significant.

*One Way Anova was used to calculate the P-value.

*Multiple Range Test by Tukey - HSD procedure was employed to identify the significant groups at $5 \%$ level.

\begin{tabular}{|c|c|c|c|}
\hline Parameters & $\begin{array}{l}\text { Control } \\
\text { Groups }\end{array}$ & $\begin{array}{c}\text { Mean+S.D } \\
(\mu)\end{array}$ & P-Value \\
\hline \multirow{2}{*}{ C.D } & IV & $57.17 \pm 1.26$ & \multirow{2}{*}{$<0.0001(\mathrm{~S})$} \\
\hline & $\mathrm{V}$ & $42.34 \pm 7.35$ & \\
\hline \multirow{2}{*}{ N.D } & IV & $10.43 \pm 1.08$ & \multirow{2}{*}{$0.005(\mathrm{~S})$} \\
\hline & $\mathrm{V}$ & $16.50 \pm 6.18$ & \\
\hline \multirow{2}{*}{$\mathrm{N}: \mathrm{C}$} & IV & $0.18 \pm 0.16$ & \multirow{2}{*}{$0.001(\mathrm{~S})$} \\
\hline & $\mathrm{V}$ & $0.39 \pm 0.16$ & \\
\hline $\begin{array}{r}\text { Table 2: Co } \\
\text { of Para } \\
\end{array}$ & rison of & $\begin{array}{l}\text { n and Stand } \\
\text { udy Group B }\end{array}$ & $\begin{array}{l}\text { Deviation } \\
\text { ontrols }\end{array}$ \\
\hline
\end{tabular}

*S-Statistically Significant.

*Student independent t-test was used to calculate the P-value.

\begin{tabular}{|c|c|c|c|}
\hline Parameters & $\begin{array}{c}\text { Groups } \\
\text { Compared }\end{array}$ & Mean \pm S.D & P-Value \\
\hline \multirow{2}{*}{ C.D } & Study Groups & $55.15 \pm 7.62$ & \multirow{2}{*}{$<0.005(\mathrm{~S})$} \\
\hline & Control I & $57.17 \pm 1.26$ & \\
\hline \multirow{2}{*}{ N.D } & Study Groups & $12.81 \pm 1.51$ & \multirow{2}{*}{$<0.005(S)$} \\
\hline & Control I & $10.42 \pm 1.07$ & \\
\hline \multirow{2}{*}{$\mathrm{N}: \mathrm{C}$} & Study Groups & $0.24 \pm 0.04$ & \multirow{2}{*}{$<0.005(\mathrm{~S})$} \\
\hline & Control I & $0.18 \pm 0.02$ & \\
\hline o & $\begin{array}{l}\text { arison of Me } \\
\text { en Study Grot }\end{array}$ & $\begin{array}{l}\text { nd SD of Pa } \\
\text { and Contro }\end{array}$ & neters \\
\hline
\end{tabular}

*S-Statistically Significant.

*Student independent t-test was used to calculate the $\mathrm{p}$-value.

\begin{tabular}{|c|c|c|c|}
\hline Parameters & $\begin{array}{c}\text { Groups } \\
\text { Compared } \\
\end{array}$ & Mean \pm S.D & P-Value \\
\hline \multirow{2}{*}{ C.D } & Study Groups & $55.15 \pm 7.62$ & \multirow{2}{*}{$<0.005(\mathrm{~S})$} \\
\hline & Control II & $42.34 \pm 7.35$ & \\
\hline \multirow{2}{*}{ N.D } & Study Groups & $12.81 \pm 1.51$ & \multirow{2}{*}{$<0.005(\mathrm{~S})$} \\
\hline & Control II & $16.50 \pm 6.18$ & \\
\hline \multirow{2}{*}{$\mathrm{N}: \mathrm{C}$} & Study Groups & $0.24 \pm 0.04$ & \multirow{2}{*}{$<0.005(\mathrm{~S})$} \\
\hline & Control II & $39 \pm 0.16$ & \\
\hline \multicolumn{4}{|c|}{$\begin{array}{c}\text { Table 4: Comparison of Mean and SD of Parameters } \\
\text { Cell Diameter, Nuclear Diameter and } \\
\text { Nuclear to Cell Diameter Ratio between Study } \\
\text { Group A - Cases and Study Group B - Control II }\end{array}$} \\
\hline
\end{tabular}

*S-Statistically Significant.

*Student's independent t-test was used to calculate the pvalue.

\section{DISCUSSION}

Individual cellular response to irritants such as tobacco varies from one person to another depending on their cellular resistance and genetic makeup at the individual level and dietary intake. ${ }^{8}$ The cells make adjustments with the changes in their environment (Adapt) to physiological needs (Physiological adaptation) and to non-lethal pathologic injury (Pathologic adaptation). $.8,9$

\section{These Adaptations Occur by following Processes}

a) Increase or decrease in their size that is atrophy and hypertrophy respectively or increase by their number that is hyperplasia.

b) By changing pathway of phenotypic differentiation of cells that is metaplasia and dysplasia.

These adaptive responses are reversible on withdrawal of stimulus. If the irritant stimulus persists for long time, cells may not be able to survive and many cells either die or progress further that is death in sustained atrophy or progression of dysplasia to carcinoma in situ. Thus, the same 
was observed even in reverse smokers where the palatal surface epithelium of different persons react to reverse smoking variously. The carcinogenicity of these lesions also found to vary and these changes can be observed in the exfoliated palatal epithelial cells.

Cowpe et al demonstrated that exfoliative cytology is capable of detecting malignant changes through estimation of ND:CD ratio using planimetric method in Papanicolaou stained smears. ${ }^{6}$ Their study concluded that 50 cells were sufficient to provide indication of malignant change and also suggested that the tissue undergoing malignant transformation typically show a reduction in $\mathrm{CD}$ before the reduction of NA. The present study represents a quantitative technique applied to the smears collected from clinically various palatal lesions (Cases), palatal carcinoma in reverse smokers (Control I) and from normal palate (Control I).

The cytomorphometric result of control groups can be explained as carcinoma group (Control II) showed significant reduction in $\mathrm{CD}$ and significant increase in ND and N:C ratio than the normal palate in non-smokers (Control I). It is a known fact that the normal cells have greater CD than ND, the reversal changes in these parameters in the present study account for malignant change from normal to carcinoma.

The decrease in CD and increased ND could be explained as first, there is less ability for the cytoplasm to transform into its more mature cell type (e.g. stratified squamous, columnar epithelium) so that there is greater immaturity to the cytoplasm of the cell with greatly increased activity. Additionally, the amount of cytoplasm the cell makes decreases relative to the amount of nucleoplasm, so that the cell diameter decreases and there is an actual increase in nuclear size which may be related to an increase in the nuclear contents required for replication. ${ }^{10}$ As a result, the nuclear-to-cytoplasmic ratio increases at times to an extreme degree. Such examples of increased activity are seen as a result of various processes acting on the cells including stimulation, replication and repair from degeneration, premalignant processes and neoplasia. ${ }^{8,9}$ Cellular diameter is found to increase in hypertrophy and decrease in the atrophy and dysplasia. Nuclear diameter is found to increase in dividing cells and dysplasia. Though, the decrease in cell diameter accounts for atrophy, at the same time increase in nuclear diameter and nuclear to cell diameter accounts for dysplastic changes in the lesions and may represent an early malignant transformation. ${ }^{11,12}$

The results in the present study showed that mean CD, mean ND and mean N:C ratio of white patches and red areas (case groups II and III) are in between control I and control II. The variation in these parameters in the present study suggests that two lesions namely red areas and white patch can be intermediate stages in the range from normal to carcinoma and represent premalignant lesions with dysplastic changes of palatal surface epithelium.

Our comparing results with the previous studies showed a similar result as shown by Cowpe et al (1988) and Ramaesh et al (1998) who reported that for experimental lesions in hamster cheek pouch epithelium, the cell volume was reduced at the dysplastic stage and became smaller until the smallest size was seen in carcinomas. ${ }^{13}$ Thus, this reduction in CD could be an early indication of malignant change and these lesions can be considered as precancerous lesions. ${ }^{10,11,12}$
Ramaesh et al reported a significant increase in the nuclear size in normal mucosal lesions with no dysplasia and further through dysplasias to squamous cell carcinoma.11,12

Similar findings of an increase in nuclear size with dysplasia and squamous cell carcinoma have been reported in cervical smears and in experimental lesions in hamster cheek. 13 Thus, this increase in ND could be an early indication of malignant change ${ }^{10,11}$ and case groups II and III were intermediate stages in the range from normal to carcinoma.

In the present study, the noticed cytomorphometric changes of palatal surface epithelial cells in the excrescences showed significant increase in mean $C D, N D$ and $\mathrm{N}: \mathrm{C}$ compared to control I. So, this suggests only proplasia and hypertrophy of the palatal surface epithelial cells, which are found to be the initial responses to the heat and smoke.1,8,9 Thus, it differs from cases II and III found to be precancerous, where there is decrease in mean CD, increase in mean ND and increase in mean $\mathrm{N}: \mathrm{C}$ compared to control I.

Our results correlate with Mehta et al (1977) who suggested that this component appears to be the initial and probably the most immediate response to the reverse smoking habit. ${ }^{1}$ So, excrescences are most transient in nature and tend to regress with the stoppage of the habit. But our results differs with Reddy et al (1973) who found that onethird of the biopsy specimens from Nicotina stomatitis showed atypical changes of the epithelium and $2.4 \%$ showed micro-invasive carcinoma and thus they concluded that Nicotina stomatitis in reverse smokers could be precancerous. ${ }^{4,14}$

Malignant potential of excrescences (Case group I), thus had variously described by various research workers. The above two contradictory statements, that is one stating that it is precancerous and the other transient nature carries their own value and could be explained as the behaviour of this lesion varies depending upon the response of two palatal epithelial components namely, palatal surface epithelium and ductal epithelium of minor salivary glands seen in posterior palate. Both the surface epithelium and ductal epithelium undergoes hyperplasia and hypertrophy initially in response to heat and chemicals released during reverse smoking.8,9,14 It is known that these cellular adaptations can resist the injury to a certain extent only beyond which the cells would check onto other protective mechanisms such as hyperkeratosis by surface epithelium.8, At this moment if the habit is discontinued, this lesion may be completely reversible.

The hypertrophied ductal openings of minor salivary glands act as portal of entry for tobacco smoke and the pseudostratified columnar epithelial lining of ducts is found to undergo squamous metaplasia in response to chronic irritation caused by heat and chemicals released during reverse smoking and this metaplastic squamous epithelium has got high malignant potential and may be responsible for malignancy in this component. 3,14 Thus, it can be concluded that if a carcinoma arises from an excrescence, it could be mainly from metaplastic squamous epithelium of ductal lining of minor salivary glands in palate, but may not from the palatal surface epithelium.

This is supported by the observations of Reddy et al (1973) that glandular region of hard palate in excrescences was the commonest site for malignancy, as they noticed dysplastic features mainly in the ductal epithelium than surface palatal epithelium and even the mild atypical changes 
noted in the surface palatal epithelium were usually confined to the mouths of ducts of the glands and too little of the surrounding epithelium. ${ }^{4}$

Though, the excrescences (Case group I) in reverse smoker's palate clinically resembles the Nicotina palati seen in pipe or cigar or bidi smokers, it differs by its clinical and biological behaviour due to its malignant potential. The reason for this malignant transformation may be due to more heat generated during reverse smoking rising the palatal temperature up to $120^{\circ} \mathrm{C}$ and also more toxins released due to tobacco and incomplete combustion of the chutta tobacco which bring malignant changes in ductal epithelium of palatal salivary glands. ${ }^{15}$

The probable reason for the results of our study in case of excrescences coinciding with the statement that this reaction is an earlier and transient in nature, may be that the smear in this component consists predominantly palatal surface epithelial cells and thus the above noticed cytomorphometric changes were related to the surface epithelium not from the ductal epithelium.

\section{CONCLUSION}

The present cytomorphometric study of palatal exfoliative mucosal smears in reverse smoking lesions reflect the histological changes of palatal mucosa. Predominantly, three types of palatal lesions were noticed at present in reverse smokers. The study concludes that excrescences represent proplastic and hyperplastic reaction of palatal surface epithelium, whereas white areas and red areas represent premalignant changes of palatal surface epithelium. This study once again confirms the premalignant nature of white lesions and red lesions as seen in other areas of oral cavity, but premalignant nature of excrescences was yet to confirm. Further studies are needed to confirm the nature of excrescences of palate in reverse smokers.

\section{Suggestions and Recommendations}

Prevalence of reverse smokers lesions of palate are still noticed at large number in these villages and this alarms the necessity of educating these villagers for discontinuance of the reverse smoking habit. Our study is a preliminary step to define malignant potential of various reverse smokers lesions through exfoliative palatal smears in reverse chutta smokers. The data recorded in the present study can be of more diagnostic value, if further studies continue in the same method in future. Proper histopathological investigations among these people needed for early detection of malignancy, especially in excrescences where carcinoma seem to arise from ducts of palatal minor salivary glands to prevent morbidity and mortality areas.

\section{ACKNOWLEDGMENTS}

I thank Dr. B. Sivapathasundaram, Prof. and Head, Department of Oral Pathology, MADC, Chennai, for his guidance and thoughtful suggestions throughout the study. Special thanks to Dr. Madhuvilekar, Chairman of Sri Sai Dental College and Hospital, Srikakulum, for facilities provided. I am grateful to Mr. Hemanth Kumar, Forest Officer, for providing necessary manpower during my study. Last but not the least, I am thankful to all the study participants who have consented and as part of the study take away all participants have been advised for good oral hygiene practices for oral disease prevention and appropriate treatment instructions were elaborated in advanced oral disease intervention accordingly.

\section{REFERENCES}

1. Mehta FS, Jalnawalla PN, Daftary DK, et al. Reverse smoking in Andhra Pradesh, India: variability of clinical and histological appearances of palatal changes. Int J Oral Surg 1977;6(2):75-83.

2. Gavarasana S, Susarla MD. Palatal mucosal changes among reverse smokers in an Indian village. Jpn J Cancer Res 1989;80(3):209-11.

3. van der Eb MM, Leyten EM, Gavarasana S, et al. Reverse smoking as a risk factor for palatal cancer: a crosssectional study in rural Andhra Pradesh, India. Int J Cancer 1993;54(5):754-8.

4. Reddy CR. Carcinoma of hard palate in India in relation to reverse smoking of chuttas. J Natl Cancer Inst 1974;53(3):615-9.

5. Reddy CR, Sharma RM, Kameswari PR, et al. Oral exfoliative cytology in female reverse smokers having stomatitis nicotina. Acta Cytol 1975;19(1):28-31.

6. Cowpe JG, Longmore RB, Green MW. Quantitative exfoliative cytology of abnormal oral mucosal smears. J R Soc Med 1988;81(9):509-13.

7. Ogden GR, Cowpe JG, Green MW. Quantitative exfoliative cytology of normal buccal mucosa: effect of smoking. J Oral Pathol Med 1990;19(2):53-5.

8. Kumar V, Abbas AK, Fauster N, et al. Cell injury, cell death and adaptations. Neoplasia. In: Robbins basic pathology. $8^{\text {th }}$ edn. New Delhi: Elsevier 2007:1-30 \& 173223.

9. Mohan H. Cellular adaptations. Chapter 19. In: Essential pathology for dental students $3^{\text {rd }}$ edn. New Delhi: Jaypee Brothers Medical publishers (P) ltd 2005:229-278.

10. Khandelwal S, Solomon MC. Cytomorphological analysis of keratinocytes in oral smears from tobacco users and oral squamous cell carcinoma lesions -- a histochemical approach. Int J Oral Sci 2010;2(1):45-52.

11. Ramaesh $\mathrm{T}$, Mendis $\mathrm{BR}$, Ratnatunga $\mathrm{N}$, et al. Cytomorphometric analysis of squames obtained from normal oral mucosa and lesions of leukoplakia and squamous cell carcinoma. J Oral Pathol Med 1998;27(2):83-6.

12. Ramaesh T, Mendis BRRN, Ratnatunga N, et al. The effect of tobacco smoking and betel quid chewing with tobacco on the buccal mucosa: a cytomorphometric analysis. J Oral Pathol Med 1999;28(9):385-8.

13. Franklinn CD, Smith CJ. Stereological analysis of histologic parameters in experimental hamster cheek pouch epithelium. J Pathol 1980;130(3):201-15.

14. Ramulu C, Raju MV, Venkatarathnam G, et al. Nicotine stomatitis and its relation to carcinoma of the hard palate in reverse smokers of chuttas. J Dent Res 1973;52(4):711-8.

15. Quigley LF, Cobb CM, Hunt EE. Measurement of oral and burning zone temperatures during conventional and reverse cigarette smoking. Arch Oral Biol 1965;10:35-44. 